\title{
FORMATION OF BINARY COMPLEXES OF Co(II), Ni(II) AND Cu(II) WITH L-DOPA IN DIOXAN-WATER MIXTURES
}

\author{
Rama Raju Bendi, Venkata Santhee Devi Karri and Nageswara Rao Gollapalli* \\ Department of Inorganic and Analytical Chemistry, Andhra University, \\ Visakhapatnam-530003, India
}

(Received January 4, 2010; revised August 31, 2010)

\begin{abstract}
Complexation of essential metal ions with (S)-2-amino-3-(3,4-dihydroxyphenyl) propanoic acid (dopa) in $(0-60 \% \mathrm{v} / \mathrm{v})$ dioxan-water mixtures has been studied $\mathrm{pH}$-metrically at a temperature of $303 \mathrm{~K}$ and an ionic strength of $0.16 \mathrm{M}$. The existence of different binary species was established from modeling studies using the computer program MINIQUAD75. The best-fit chemical models were selected based on statistical parameters like crystallographic $\mathrm{R}$ factor and sum of the squares of residuals in mass-balance equations. The models for binary complex systems contain the chemical species $\mathrm{ML}, \mathrm{ML}_{2}, \mathrm{MLH}, \mathrm{ML}_{2} \mathrm{H}$ and $\mathrm{ML}_{2} \mathrm{H}_{2}$ for $\mathrm{Co}$ (II), $\mathrm{Ni}$ (II) and $\mathrm{Cu}$ (II) in dioxan-water mixtures. The trend in the variation of stability constants with change in the mole fraction of the medium was explained based on electrostatic and non-electrostatic forces. Distribution of the species with $\mathrm{pH}$ at different compositions of dioxan-water mixtures was also presented.
\end{abstract}

KEY WORDS: Binary species, Stability constants, Metal, Dopa, Dioxan, pH-metry

\section{INTRODUCTION}

Cobalt(II), nickel(II) and copper(II) are associated with several enzymes [1, 2] and any variation in their concentration leads to metabolic disorders [3]. Hence speciation study of essential metal ion complexes is useful to understand the role played by the active site cavities in biological molecules and the bonding behavior of protein residues with the metal ions. In biological fluids, metal ions exist in non-exchangeable form as in metallo-proteins or loosely bound to some bioligands as in metal-activated proteins. The loosely bound metal ions are in equilibrium with simple metal ions present in the bio-fluids. These simultaneous equilibria involving a variety of metal ions and ligands are important in bio-fluids [4].

The formation of metal complexes of dopa was reviewed by Gergely [5] and Pettit [6]. Dopa is a naturally occurring dietary supplement and psychoactive drug found in certain kinds of food and herbs. Besides its natural and essential biological role dopa is a popular drug in the treatment of manganese poisoning and Parkinson's disease [7,8] which are accompanied by neurologically similar sequels [9]. Dopa is also a popular drug in the treatment of dopamine-reponsive dystonia and to increase dopamine concentration, since it is capable of crossing the blood brain barrier, where dopamine itself cannot. Once dopa enters the central nervous system (CNS) it is converted into dopamine by the enzyme aromatic L-amino acid decarboxylase, also known as dopa decarboxylase. However, conversion to dopamine also occurs in the peripheral tissues, causing adverse effects and decreasing the availability of dopamine to the CNS; so it is the standard practice to co-administer a peripheral dopa decarboxylase inhibitor.

1,4-Dioxan [10] is a non-polar solvent capable of acting as hydrogen bond acceptor with random structure. Dioxan also found in fumigants and automotive coolant. It is also used as a foaming agent and appears as an accidental byproduct of the ethoxylation [11] process in cosmetics manufacturing. It may contaminate cosmetics and personal care products such as deodorants, shampoos, toothpastes and mouthwashes [12].

Cobalt is essential for the production of red blood cells and cobalamin and it acts as the substrate for the final enzymatic reaction that yields the active coenzyme derivatives of

*Corresponding author. E-mail: gollapallinr@yahoo.com 
cyanocobalamin and aqua cobalamin. Although cobalt is an essential element for life in minute amounts (10 mg/day), at higher levels of exposure it shows mutagenic and carcinogenic effects [13]. Minot and Murphy [14] discovered that pernicious anemia can be treated by feeding the patient with large amounts of liver which contains vitamin $B_{12}$. Trace amounts of vitamin $B_{12}$ are essential for the synthesis of hemoglobin. Its deficiency causes anemia.

Nickel plays numerous roles in the biology of microorganisms and plants $[15,16]$. Urease, an enzyme which assists in the hydrolysis of urea, contains nickel. The NiFe-hydrogenases contain nickel in addition to iron-sulfur clusters [17]. A nickel-tetrapyrrole coenzyme, F430, is present in the methyl coenzyme $\mathrm{M}$ reductase which powers methanogenic archaea. Other nickel-containing enzymes include a class of superoxide dismutase [18] and a glyoxalase [19].

Copper is essential in all plants and animals. The human body contains copper at a level of about 1.4 to $2.1 \mathrm{mg} / \mathrm{kg}$ weight of human body [20]. Copper is distributed widely in the body and occurs in liver, muscle and bone. Copper is transported in the blood stream on a plasma protein called ceruloplasmin. When copper is first absorbed in the gut it is transported to the liver bound to albumin. Copper metabolism and excretion is controlled delivery of copper to the liver by ceruloplasmin, where it is excreted in bile. Copper is found in a variety of enzymes, like cytochrome $\mathrm{C}$ oxidase and superoxide dismutase. The recommended dietary allowances for copper in normal healthy adults is $0.9 \mathrm{mg} /$ day [21]. Because of its role in facilitating iron uptake, copper deficiency can often produce anemia-like symptoms. In humans, the symptoms of Wilson's disease are caused by an accumulation of copper in body tissues. In addition to its enzymatic roles, copper is used for biological electron transport. The blue copper proteins that participate in electron transport include azurin and plastocyanin.

Hence, speciation studies of the title systems have been undertaken based on their involvement in various physiological reactions. Protonation equlibria of L-dopa in dioxan-water mixtures have already been reported from this laboratory [22].

\section{Materials and methods}

\section{EXPERIMENTAL}

Dioxan (Finar, India) was used as received. Aqueous solutions of 0.05 M L-dopa (Loba, India) and $0.2 \mathrm{M}$ hydrochloric acid (Qualigens, India) were prepared in triple-distilled deionized water. Sodium chloride (Qualigens, India) of $2 \mathrm{M}$ was prepared to maintain the ionic strength in the titrand. Solutions of $\mathrm{Co}(\mathrm{II}), \mathrm{Ni}(\mathrm{II})$ and $\mathrm{Cu}$ (II) chlorides were prepared. To increase the solubility of dopa and to suppress the hydrolysis of metal salts, mineral acid concentration in the above solutions was maintained at 0.05 M. A 0.4 M Sodium hydroxide (Qualigens, India) of was prepared. All the solutions were standardized by standard methods. To assess the errors that might have crept into the determination of the concentrations, the data were subjected to analysis of variance of one way classification (ANOVA) [23]. The strengths of alkali and mineral acid were determined using the Gran plot method [24, 25].

\section{Apparatus}

The titrimetric data were obtained using ELICO (Model LI-120, India) pH meter (readability 0.01 ), which was calibrated with $0.05 \mathrm{M}$ potassium hydrogen phthalate in acidic region and 0.01 $\mathrm{M}$ borax solution in basic region. The glass electrode was equilibrated in a well-stirred dioxanwater mixture containing the inert electrolyte. All the titrations were carried out in the medium containing varying concentrations of dioxan-water mixtures $(0-60 \% \mathrm{v} / \mathrm{v})$ by maintaining an ionic strength of $0.16 \mathrm{M}$ with sodium chloride at $303.0 \pm 0.1 \mathrm{~K}$. The effect of variation in asymmetry potential, liquid junction potential, activity coefficient, sodium ion error and 
dissolved carbon dioxide on the response of glass electrode was accounted for in the form of correction factor [26, 27].

\section{Procedure}

Initially strong acid was titrated against alkali at regular intervals to check the complete equilibration of the glass electrode. Then the calomel electrode was refilled with dioxan-water mixture of equivalent composition as that of the titrand. In each of the titrations, the titrand consisted of approximately $1 \mathrm{mmol}$ mineral acid in a total volume of $50 \mathrm{~mL}$. Titrations with different ratios (1:2.5, 1:3.75 and 1:5) of metal-to-ligand were carried out with $0.4 \mathrm{M}$ sodium hydroxide [28].

\section{Modeling strategy}

The computer program SCPHD [29] was used to calculate the correction factor. By using $\mathrm{pH}$ metric titration data, the binary stability constants were calculated with the computer program MINIQUAD75 [30] which exploits the advantage of constrained least-squares method in the initial refinement and reliable convergence of Marquardt algorithm. During the refinement of binary systems, the correction factor and protonation constants of dopa were fixed.

\section{Theme of the work}

In the present study the change in $\left[\mathrm{H}^{+}\right]$or $\mathrm{pH}$ of the titrand was monitored with the addition of alkali. The basic premise of $\mathrm{pH}$ metric determination of stability constants is that the ligand is a weak acid/base. When the ligand (LH) forms a complex with metal ion one or more protons are released and these protons are measured in the form of change in $\mathrm{pH}$. For example, if the following two equilibria exist in solutions.

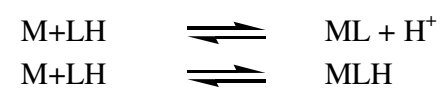

The first equilibrium can be detected $\mathrm{pH}$ metrically but not the second. This change in $\mathrm{pH}$ is monitored using glass electrode and the stability constants of the complexes are calculated by computer program on the basis of mass balance equation. From the stability constants, MINIQUAD75 program calculates the concentration of species.

Different models were refined by MINIQUAD75 program. The best-fit model was chosen based on the statistical parameters which were outputted by MINIQUAD75. These models represented the alkalimetric titration data and the equilibria existing in the solution.

\section{RESULTS AND DISCUSSION}

The results of the best-fit models that contain the stoichiometry of the complex species and their overall formation constants along with some of the important statistical parameters are given in Table 1 . Very low standard deviation in overall stability constants $(\log \beta)$ signifies the precision of these constants. The small values of $U_{\text {corr }}$ (sum of squares of deviations in concentrations of ligand and hydrogen ion at all experimental points corrected for degrees of freedom), small values of mean, standard deviation and mean deviation for the systems are validated by the residual analysis [31]. 
Table 1. Parameters of best fit chemical models of $\mathrm{Co}(\mathrm{II}), \mathrm{Ni}(\mathrm{II})$ and $\mathrm{Cu}$ (II)-dopa complexes in dioxan- water mixtures.

\begin{tabular}{|c|c|c|c|c|c|c|c|c|c|c|c|c|}
\hline \multirow{2}{*}{\begin{tabular}{|c|}
$\%$ v/v \\
Dioxan
\end{tabular}} & \multicolumn{5}{|c|}{$\log \beta_{\mathrm{mlh}}(\mathrm{SD})$} & \multirow{2}{*}{$\begin{array}{l}\mathrm{pH}- \\
\text { Range }\end{array}$} & \multirow[t]{2}{*}{ NP } & \multirow[t]{2}{*}{$\mathrm{U}_{\text {corr }}$} & \multirow[t]{2}{*}{$\chi^{2}$} & \multirow{2}{*}{$\begin{array}{l}\text { Skew } \\
\text { ness }\end{array}$} & \multirow{2}{*}{$\begin{array}{l}\text { Kurto } \\
\text { sis }\end{array}$} & \multirow{2}{*}{$\begin{array}{l}\mathrm{R}- \\
\text { factor }\end{array}$} \\
\hline & $\mathrm{ML}$ & MLH & $\mathrm{ML}_{2}$ & $\mathrm{ML}_{2} \mathrm{H}$ & $\mathrm{ML}_{2} \mathrm{H}_{2}$ & & & & & & & \\
\hline \multicolumn{13}{|c|}{$\mathrm{Co}$ (II) } \\
\hline 0 & $5.98(9)$ & $13.28(20)$ & $10.14(3)$ & $19.10(5)$ & $27.46(2)$ & $7.1-9.3$ & 32 & 1.44 & 12.17 & 0.05 & 2.61 & 0.009 \\
\hline 10 & $5.96(19)$ & 13.77(19) & $9.59(21)$ & $18.76(38)$ & 26.91(34) & $6.0-9.0$ & 26 & 3.99 & 14.10 & -0.36 & 4.35 & 0.013 \\
\hline 20 & $7.67(34)$ & 15.42(19) & $12.30(18)$ & $21.76(17)$ & $29.27(36)$ & $7.8-10.5$ & 15 & 1.4 & 12.78 & -0.72 & 3.56 & 0.007 \\
\hline 30 & $7.94(30)$ & $15.59(7)$ & $11.62(7)$ & $21.73(7)$ & $30.10(6)$ & $6.0-10.0$ & 13 & 1.16 & 7.97 & -0.38 & 2.92 & 0.006 \\
\hline 40 & $8.45(33)$ & 15.71(3) & $12.04(4)$ & 22.31(3) & $30.57(3)$ & $7.5-10.2$ & 22 & 6.02 & 4.79 & -0.17 & 3.50 & 0.016 \\
\hline 50 & $8.16(34)$ & $15.86(8)$ & $12.66(8)$ & $22.95(7)$ & $30.97(6)$ & $6.0-10.5$ & 39 & 6.9 & 101.7 & 0.60 & 5.37 & 0.021 \\
\hline 60 & $9.73(8)$ & 16.82(9) & $14.42(10)$ & 24.73(9) & $32.76(8)$ & $6.3-10.8$ & 31 & 7.26 & 12.89 & -0.68 & 2.37 & 0.020 \\
\hline \multicolumn{13}{|c|}{$\mathrm{Ni}$ (II) } \\
\hline 0 & $9.22(11)$ & 15.71(39) & $15.57(15)$ & $23.31(15)$ & $30.70(41)$ & $4.0-8.8$ & 31 & 10.4 & 20.31 & -1.68 & 8.94 & 0.025 \\
\hline 10 & $8.54(42)$ & $15.33(8)$ & $14.14(8)$ & $22.36(9)$ & $29.90(6)$ & $6.0-9.2$ & 12 & 1.8 & 4.44 & -0.10 & 2.54 & 0.007 \\
\hline 20 & $9.70(3)$ & $16.64(3)$ & $14.56(4)$ & $23.71(5)$ & $31.42(36)$ & $5.0-10.0$ & 43 & 2.79 & 10.97 & -0.32 & 3.05 & 0.013 \\
\hline 30 & $9.37(8)$ & 16.11(9) & $12.07(12)$ & $22.34(14)$ & $32.49(42)$ & $3.0-10.5$ & 12 & 20.7 & 24.89 & 0.20 & 5.03 & 0.041 \\
\hline 40 & $9.73(28)$ & $16.93(15)$ & $15.39(12)$ & $24.72(13)$ & $32.67(14)$ & $6.0-10.5$ & 16 & 0.16 & 29.67 & 1.97 & 11.14 & 0.002 \\
\hline 50 & $9.70(34)$ & $16.80(16)$ & $12.43(23)$ & 23.67(19) & $32.93(14)$ & $6.0-10.8$ & 18 & 1.86 & 5.33 & 0.39 & 2.01 & 0.013 \\
\hline 60 & $9.59(8)$ & $17.45(8)$ & $13.56(13)$ & $24.12(26)$ & $33.76(14)$ & $4.2-10.8$ & 18 & 0.23 & 6.52 & -0.62 & 5.95 & 0.005 \\
\hline \multicolumn{13}{|c|}{$\mathrm{Cu}(\mathrm{II})$} \\
\hline 0 & $11.92(8)$ & $17.34(5)$ & $17.10(12)$ & $25.94(12)$ & $32.57(63)$ & $5.8-9.0$ & 21 & 0.88 & 7.98 & 0.22 & 5.22 & 0.007 \\
\hline 10 & $11.73(27)$ & $17.08(8)$ & 16.11(19) & $25.99(16)$ & $33.46(9)$ & \begin{tabular}{|l|}
$4.0-9.1$ \\
\end{tabular} & 25 & 0.15 & 2.93 & -0.14 & 2.37 & 0.005 \\
\hline 20 & $13.55(19)$ & 18.51(5) & $19.57(14)$ & $28.73(13)$ & $36.05(7)$ & $3.0-9.5$ & 36 & 0.48 & 7.26 & -0.23 & 3.34 & 0.004 \\
\hline 30 & $14.86(2)$ & $18.93(1)$ & $19.70(8)$ & $29.47(7)$ & $37.91(24)$ & $4.5-10.0$ & 19 & 3.64 & 8.85 & -0.18 & 5.13 & 0.013 \\
\hline 40 & $14.64(12)$ & $19.39(2)$ & $20.29(9)$ & $29.67(4)$ & $37.43(2)$ & $3.6-9.0$ & 17 & 0.26 & 4.13 & 0.21 & 2.58 & 0.002 \\
\hline 50 & $13.92(23)$ & $19.42(3)$ & $19.65(12)$ & $29.08(12)$ & $37.36(8)$ & $3.6-10.0$ & 18 & 0.14 & 5.51 & -0.22 & 3.93 & 0.003 \\
\hline 60 & $15.96(9)$ & $20.19(8)$ & $21.22(15)$ & $30.38(19)$ & $38.32(18)$ & $3.0-9.5$ & 21 & 0.8 & 17.38 & 0.19 & 5.53 & 0.004 \\
\hline
\end{tabular}

$\mathrm{U}_{\text {corr }}=\mathrm{U} /(\mathrm{NP}-\mathrm{m}) \times 10^{8} ; \mathrm{NP}=$ number of points; $\mathrm{m}=$ number of constants; $\mathrm{SD}=$ standard deviation.

\section{Residual analysis}

In data analysis with least squares methods, the residuals (the differences between the experimental data and the data simulated based on model parameters) are assumed to follow Gaussian or normal distribution. When the data are fit into the models, the residuals should ideally be equal to zero. If statistical measures of the residuals and the errors are assumed in the models are not significantly different from each other, the model is said to be adequate. Further, a model is considered adequate only if the residuals do not show any trend. Respecting the hypothesis that the errors are random following normal distribution in the least squares analysis, the residuals are tested for normal distribution. Such tests are $\chi^{2}$, skewness, kurtosis and $\mathrm{R}$ factor. These statistical parameters show that the best-fit models portray the metal-ligand species in DOX-water mixtures, as discussed below.

Kurtosis is the measure of the peakedness of the error distribution near a model value. For an ideal normal distribution kurtosis value should be three (mesokurtic). If the calculated kurtosis is less than three, the peak of the error distribution curve is flat (platykurtic) and if the kurtosis is greater than three, the distribution shall have sharp peak (leptokurtic). The kurtosis values in the present study indicate that the residuals form leptokurtic pattern.

The values of skewness (shape of the error distribution profile) recorded in Table 1 are between -0.72 and 0.60 for $\mathrm{Co}(\mathrm{II}),-1.68$ and 1.97 for $\mathrm{Ni}$ (II) and -0.23 and 0.22 for $\mathrm{Cu}$ (II). These data evince that the residuals form a part of normal distribution; hence, least-squares method can be applied to the present data. The low crystallographic R-values given in Table 1 indicate the sufficiency of the model. The Hamilton's R-factor ratio test was developed in crystallographic analysis to decide the need for inclusion of additional terms in the model. The test finds

Bull. Chem. Soc. Ethiop. 2011, 25(1) 
application in complex equilibria to decide whether inclusion of more species in the model is necessary or not. In $\mathrm{pH}$ metric method the readability of the $\mathrm{pH}$ meter is taken as $\mathrm{R}_{\text {limit, }}$ which represents the upper boundary of $\mathrm{R}$ beyond which the model bears no significance. When different values are obtained for models containing different numbers of species, the models whose $\mathrm{R}$ values are greater than $\mathrm{R}$-table are rejected. These statistical parameters show that the best fit models portray the metal-ligand species in DOX-water media.

\section{Effect of systematic errors on best fit model}

In order to rely upon the best fit chemical model for critical evaluation and application under varied experimental conditions with different accuracies of data acquisition, an investigation was made by introducing pessimistic errors in the influential parameters like concentrations of alkali, mineral acid, ligand and metal (Table 2). The order of the ingredients that influence the magnitudes of stability constants due to incorporation of errors is alkali $>$ acid $>$ ligand $>$ metal. Some species were even rejected when errors are introduced in the concentrations. The rejection of some species and increased standard deviations in the stability constants on introduction of errors conform the appropriateness of the chosen best-fit models. This study also indicates the relative sensitivities of model parameters.

Table 2. Effect of errors in influential parameters on Ni-dopa complex stability constants in $60 \% \mathrm{v} / \mathrm{v}$ dioxan-water mixture.

\begin{tabular}{|l|c|l|l|l|l|l|}
\hline Ingredient & \multirow{2}{*}{ \% Error } & \multicolumn{5}{|l|}{$\log \beta(\mathrm{SD})$} \\
\cline { 2 - 7 } & & $\mathrm{ML}$ & $\mathrm{MLH}$ & $\mathrm{ML}_{2}$ & $\mathrm{ML}_{2} \mathrm{H}$ & $\mathrm{ML}_{2} \mathrm{H}_{2}$ \\
\hline & 0 & $9.59(8)$ & $17.45(8)$ & $13.56(13)$ & $24.12(26)$ & $33.76(14)$ \\
\hline \multirow{4}{*}{ Alkali } & -5 & $5.61(37)$ & $16.29(28)$ & Rejected & Rejected & $29.53(93)$ \\
\cline { 2 - 7 } & -2 & Rejected & $17.03(13)$ & $11.64(25)$ & $22.56(23)$ & $32.60(21)$ \\
\cline { 2 - 7 } & 2 & $11.75(18)$ & $18.12(15)$ & $15.36(20)$ & Rejected & Rejected \\
\cline { 2 - 7 } & 5 & $13.27(57)$ & $18.96(57)$ & $18.20(63)$ & Rejected & Rejected \\
\hline \multirow{5}{*}{ Acid } & -5 & $13.22(50)$ & $18.98(50)$ & $17.72(54)$ & Rejected & Rejected \\
\cline { 2 - 7 } & -2 & $11.64(51)$ & $18.12(14)$ & $15.29(25)$ & $25.20(97)$ & $33.83(32)$ \\
\cline { 2 - 7 } & 2 & Rejected & $17.02(13)$ & $11.97(21)$ & $22.81(20)$ & $32.78(18)$ \\
\cline { 2 - 7 } & 5 & $6.28(36)$ & $16.40(28)$ & Rejected & Rejected & $30.25(56)$ \\
\hline \multirow{5}{*}{ Metal } & -5 & $9.82(11)$ & $17.45(7)$ & $13.94(9)$ & $24.40(9)$ & $33.89(8)$ \\
\cline { 2 - 7 } & -2 & $9.80(12)$ & $17.45(8)$ & $13.73(10)$ & $24.30(15)$ & $33.84(10)$ \\
\cline { 2 - 7 } & 2 & $9.85(17)$ & $17.45(10)$ & $13.36(38)$ & $23.94(98)$ & $33.69(40)$ \\
\cline { 2 - 7 } & 5 & $9.89(17)$ & $17.44(10)$ & $13.07(62)$ & $23.76(13)$ & $33.63(44)$ \\
\cline { 2 - 7 } & -5 & $9.64(8)$ & $17.51(9)$ & $13.67(55)$ & $23.45(61)$ & $33.47(14)$ \\
\cline { 2 - 7 } & -2 & $9.65(11)$ & $17.49(10)$ & $13.49(73)$ & $23.39(65)$ & $33.50(12)$ \\
\cline { 2 - 7 } & 2 & $9.68(12)$ & $17.44(7)$ & $13.48(10)$ & $24.14(10)$ & $33.75(8)$ \\
\cline { 2 - 7 } & 5 & $9.68(12)$ & $17.43(7)$ & $13.32(10)$ & $24.00(11)$ & $33.66(9)$ \\
\hline
\end{tabular}

Effect of solvent

The dioxan-water mixtures are the combination of aprotic and protic solvents with wide range of dielectric constants and with good solubility for polar as well as non-polar solutes. The cosolvent induced increased basicity [10] of dioxan-water mixtures, increases the stabilization of protons. At the same time the coordinating solvent (dioxan) competes with the ligands for coordination with the metals. This decreases the stability of the complexes. Hence, the stability of the complex is expected to either increase or decrease.

The variation of overall stability constant values with co-solvent content depends upon two factors, viz., electrostatic and non-electrostatic. Born's [32] classical treatment holds good in 
accounting for the electrostatic contribution to the free energy change. According to this treatment, the energy of electrostatic interaction is related to dielectric constants. The trends of stability constant $(\log \beta)$ values of complexes of dopa with 1/D (D is the dielectric constant of the medium) of dioxan-water mixture are given Figure 1. The trend is almost linear which indicates that the dielectric constant or long range interactions are responsible for the stability trend. This linear increase indicates the dominance of the structure-forming nature of dioxan over the complexing ability.
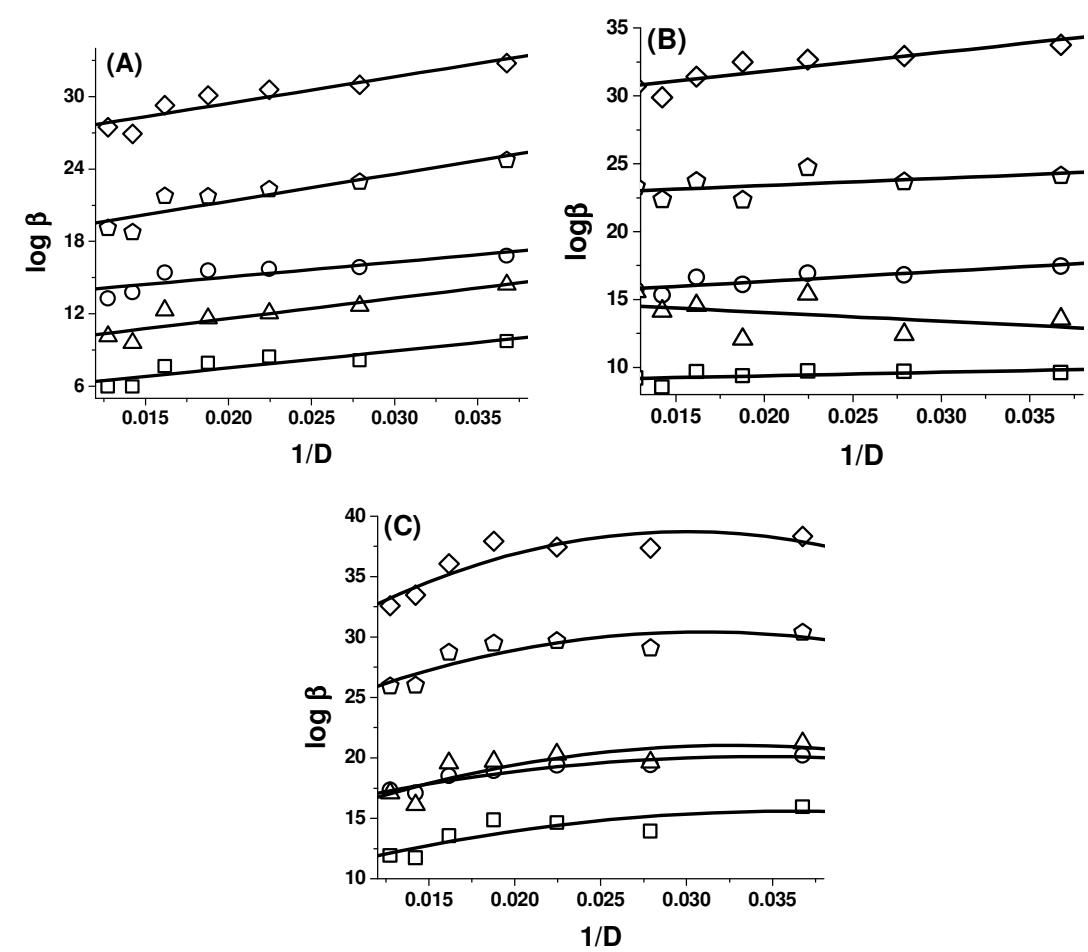

Figure 1. Variation of stability constant values of metal-dopa complexes with reciprocal of dielectric constant (1/D) of dioxan-water mixtures: (A) $\mathrm{Co}(\mathrm{II}),(\mathrm{B}) \mathrm{Ni}(\mathrm{II}),(\mathrm{C}) \mathrm{Cu}$ (II); (口) $\log \beta_{\mathrm{ML}},(\Delta) \log _{\beta_{\mathrm{ML}_{2}}}$, (०) $\log \beta_{\mathrm{MLH}},(\triangle) \log _{\beta_{\mathrm{ML}_{2} \mathrm{H}}},(\diamond) \log _{\beta_{\mathrm{ML}_{2} \mathrm{H}_{2}}}$.

\section{Distribution diagrams}

Dopa contains two ionizable phenolic protons (catecholate) in addition to carboxylic and amino protons. The different forms of dopa are $\mathrm{LH}_{4}{ }^{+}, \mathrm{LH}_{3}, \mathrm{LH}_{2}^{-}, \mathrm{LH}^{2-}$ and $\mathrm{L}^{3-}$ in the $\mathrm{pH}$ range 1.8-4.0, $2.0-10.0,8.0-11.0,10.0-12.0,>13.0$, respectively. Hence, the plausible binary metal-ligand complexes can be predicted from these data. The present investigation reveals the existence of ML, MLH, ML $2, \mathrm{ML}_{2} \mathrm{H}$ and $\mathrm{ML}_{2} \mathrm{H}_{2}$ for $\mathrm{Co}(\mathrm{II}), \mathrm{Ni}(\mathrm{II})$ and $\mathrm{Cu}(\mathrm{II})$. $\mathrm{MLH}$ and $\mathrm{ML}_{2} \mathrm{H}_{2}$ are formed simultaneously and their percentages increase in the same order with increase in $\mathrm{pH}$. Deprotonation of $\mathrm{ML}_{2} \mathrm{H}_{2}$ and $\mathrm{ML}_{2} \mathrm{H}$ forms $\mathrm{ML}_{2}$ at higher $\mathrm{pH}$. The formation of various binary complex species is shown in the following equilibria:

$$
\begin{aligned}
& \mathrm{M}(\mathrm{II})+\mathrm{LH}_{4}^{+} \leftrightarrow \mathrm{MLH}_{3}{ }^{2+}+\mathrm{H}^{+} \\
& \mathrm{MLH}_{3}{ }^{2+} \leftrightarrow \mathrm{MLH}_{2}{ }^{+}+\mathrm{H}^{+}
\end{aligned}
$$




$$
\begin{aligned}
& \mathrm{M}(\mathrm{II})+\mathrm{LH}_{3} \leftrightarrow \mathrm{MLH}_{2}^{+}+\mathrm{H}^{+} \\
& \mathrm{MLH}_{2}^{+} \leftrightarrow \mathrm{MLH}+\mathrm{H}^{+} \\
& \mathrm{M}(\mathrm{II})+\mathrm{LH}_{2}^{-} \leftrightarrow \mathrm{MLH}+\mathrm{H}^{+} \\
& \mathrm{M}(\mathrm{II})+\mathrm{LH}^{2-} \leftrightarrow \mathrm{ML}^{-}+\mathrm{H}^{+} \\
& \mathrm{MLH} \leftrightarrow \mathrm{ML}^{-}+\mathrm{H}^{+} \\
& \mathrm{M}(\mathrm{II})+2 \mathrm{LH}_{3} \leftrightarrow \mathrm{ML}_{2} \mathrm{H}_{4}+2 \mathrm{H}^{+} \\
& \mathrm{MLH}_{2}^{+}+\mathrm{LH}_{3} \leftrightarrow \mathrm{ML}_{2} \mathrm{H}_{4}+2 \mathrm{H}^{+} \\
& \mathrm{ML}_{2} \mathrm{H}_{4} \leftrightarrow \mathrm{ML}_{2} \mathrm{H}_{3}^{-}+\mathrm{H}^{+} \\
& \mathrm{MLH}_{2}{ }^{+}+\mathrm{LH}_{2}^{-} \leftrightarrow \mathrm{ML}_{2} \mathrm{H}_{3}{ }^{-}+\mathrm{H}^{+} \\
& \mathrm{ML}_{2} \mathrm{H}_{3}^{-} \leftrightarrow \mathrm{ML}_{2} \mathrm{H}_{2}^{2-}+\mathrm{H}^{+} \\
& \mathrm{M}(\mathrm{II})+2 \mathrm{LH}_{2}^{-} \leftrightarrow \mathrm{ML}_{2} \mathrm{H}_{2}{ }^{2-}+2 \mathrm{H}^{+} \\
& \mathrm{ML}_{2} \mathrm{H}_{2}{ }^{2-} \leftrightarrow \mathrm{ML}_{2} \mathrm{H}^{3-}+\mathrm{H}^{+} \\
& \mathrm{ML}_{2} \mathrm{H}^{3-} \leftrightarrow \mathrm{ML}_{2}^{4-}+\mathrm{H}^{+} \\
& \mathrm{M}(\mathrm{II})+2 \mathrm{LH}^{2-} \leftrightarrow \mathrm{ML}_{2}^{4-}+2 \mathrm{H}^{+}
\end{aligned}
$$
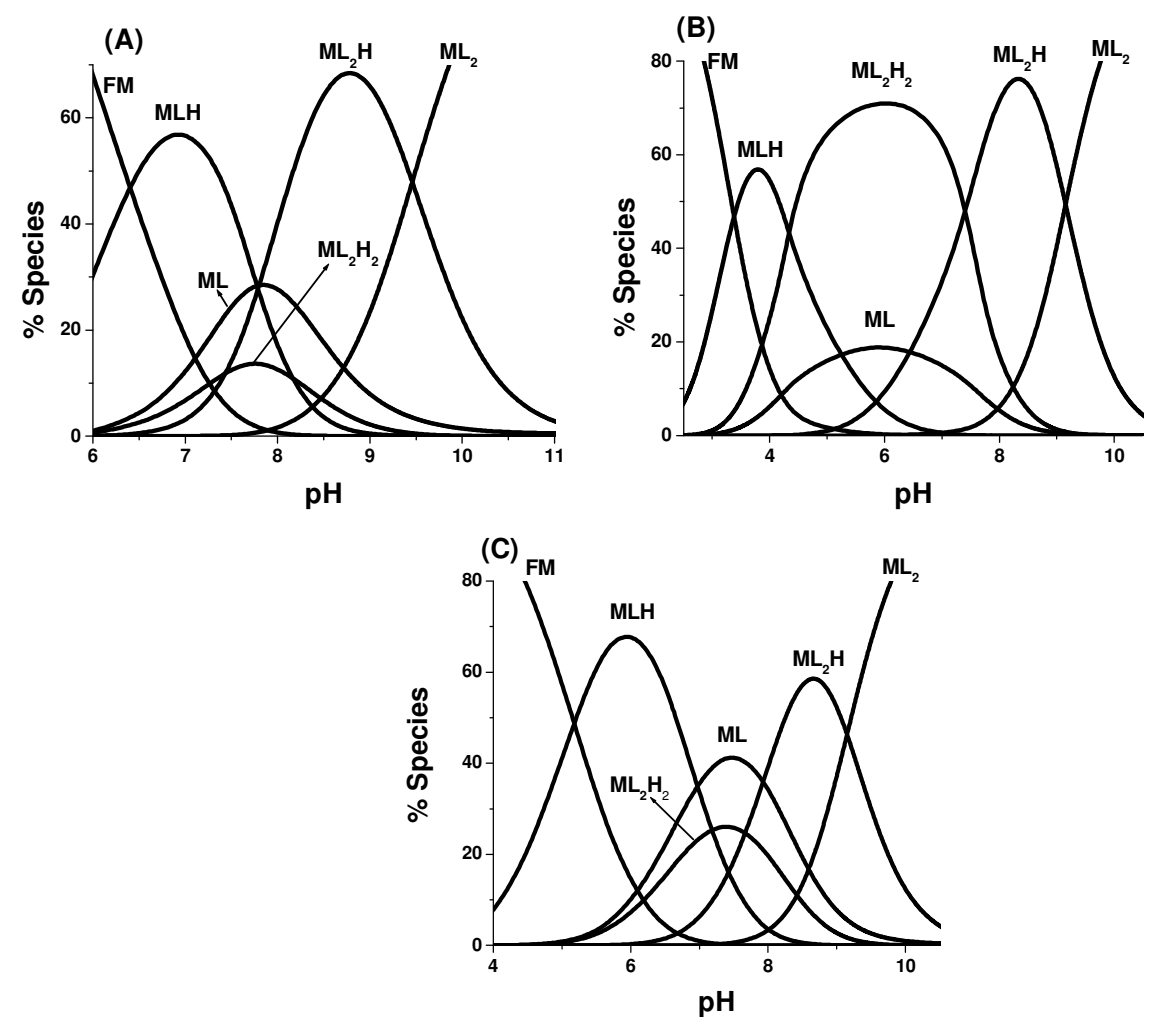

Figure 2. Distribution diagrams of binary complexes of dopa in $20 \% \mathrm{v} / \mathrm{v}$ dioxan-water mixture: (A) $\mathrm{Co}(\mathrm{II}),(\mathrm{B}) \mathrm{Ni}(\mathrm{II})$ and (C) $\mathrm{Cu}(\mathrm{II})$.

The species $\mathrm{MLH}_{3}{ }^{2-}, \mathrm{MLH}_{2}{ }^{+}, \mathrm{ML}_{2} \mathrm{H}_{4}$ and $\mathrm{ML}_{2} \mathrm{H}_{3}{ }^{-}$could not be detected in the present study probably because they are formed at very low $\mathrm{pH}$ or they might have been quickly deprotonated. 
Some typical distribution diagrams in dioxan-water mixtures are shown in Figure 2. They indicate that the binary complexes of $\mathrm{Co}(\mathrm{II}), \mathrm{Ni}(\mathrm{II})$ and $\mathrm{Cu}$ (II) are formed in the $\mathrm{pH}$ range 2.011.0. Figure 2A represents the formation of Co-dopa complexes. The species ML, MLH, $\mathrm{ML}_{2}$, $\mathrm{ML}_{2} \mathrm{H}$ and $\mathrm{ML}_{2} \mathrm{H}_{2}$ are formed in the $\mathrm{pH}$ range of 6.0-10.8. Beyond a $\mathrm{pH}$ of 9.5, successive deprotonation of $\mathrm{ML}_{2} \mathrm{H}_{2}$ form $\mathrm{ML}_{2} \mathrm{H}$ and $\mathrm{ML}_{2}$ (Equilibria 14 and 15).

Figure 2B shows formation of Ni-dopa complexes. The concentration of $\mathrm{ML}_{2} \mathrm{H}_{2}$ species decreased, while the concentration of $\mathrm{ML}_{2} \mathrm{H}$ and $\mathrm{ML}_{2}$ increased in the $\mathrm{pH}$ range 5.0-10.8 (Equilibria 14 and 15). At lower $\mathrm{pH}$ range (6.0-9.0) $\mathrm{MLH}_{2}$ species, having less stability in the medium, is quickly deprotonated to form MLH species (Equilibrium 4). Figure 2C shows the formation of $\mathrm{Cu}$-dopa complexes in the $\mathrm{pH}$ range 4.5-10.0. The concentration of $\mathrm{ML}_{2} \mathrm{H}_{2}$ species is decreased, while the concentration of $\mathrm{ML}_{2} \mathrm{H}$ and $\mathrm{ML}_{2}$ are increased in the $\mathrm{pH}$ range 8.8-9.5 (Equilibria 14 and 15). Similarly the concentration of MLH is decreased as the concentration of ML is increased (Equilibrium 4).

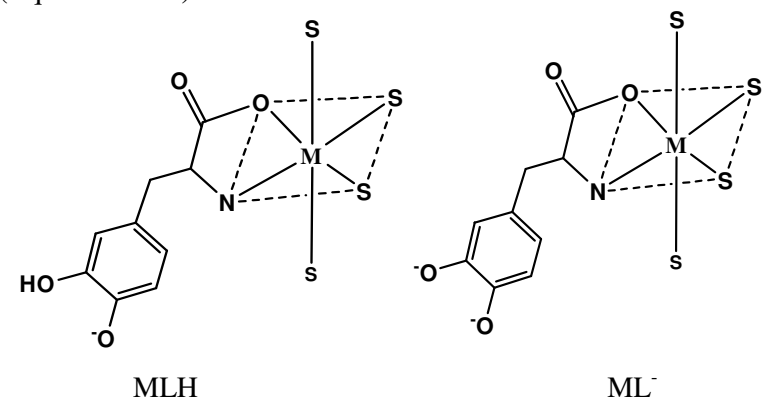

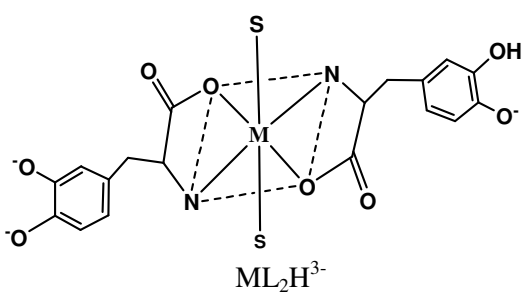

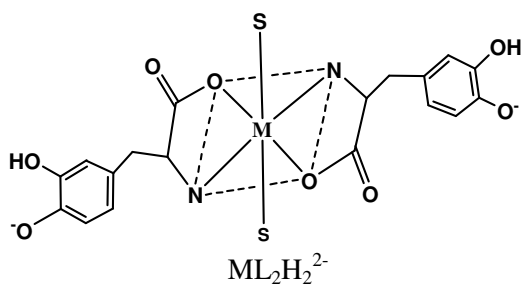

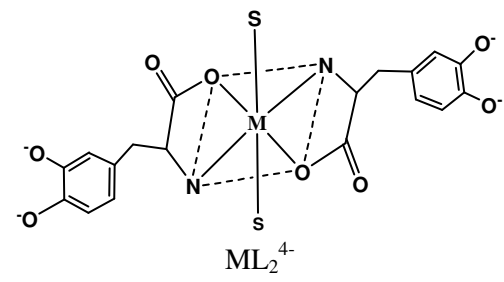

Figure 3. Structure of L-dopa complexes where $\mathrm{S}$ is either solvent or water molecules.

\section{Structures of complexes}

When the second donor site of dopa is a nitrogen atom, marked bidentate behavior is frequently found, more so when the additional chelation results in a five or six membered ring (Figure 3). Octahedral structures are proposed to the complexes of all the metal ions. The VSEPR theory suggests that $\mathrm{Co}(\mathrm{II}), \mathrm{Ni}(\mathrm{II})$ and $\mathrm{Cu}(\mathrm{II})$ complexes shall be octahedral because there are six outer electron pairs. 
Amino nitrogen atoms can associate with hydrogen ions in physiological $\mathrm{pH}$ ranges. Hence, there is often significant competition between hydrogen and metal ion for this second donor site. This situation results in the simultaneous existence of a number of equilibria producing an array of successively protonated complexes. Hence, protonated complex species are detected in the present study. Amino nitrogen and carboxyl oxygen of dopa participate in bonding with metal ions [33]. This argument supports the structures of complexes proposed in Figure 3. Gergely and Kiss [34] assumed that the structures (I), (II) and (III) proposed for $\mathrm{ML}_{2} \mathrm{H}_{2}{ }^{2-}$ (Figure 4) are all present in equilibrium with one another. The present study supports the structure of the complexes given in Figure 3 where dopa is bonded to metal through amino acid side chain rather than phenolic oxygens, because the study is below a $\mathrm{pH}$ of 10 where the second phenolic group is not deprotonated.

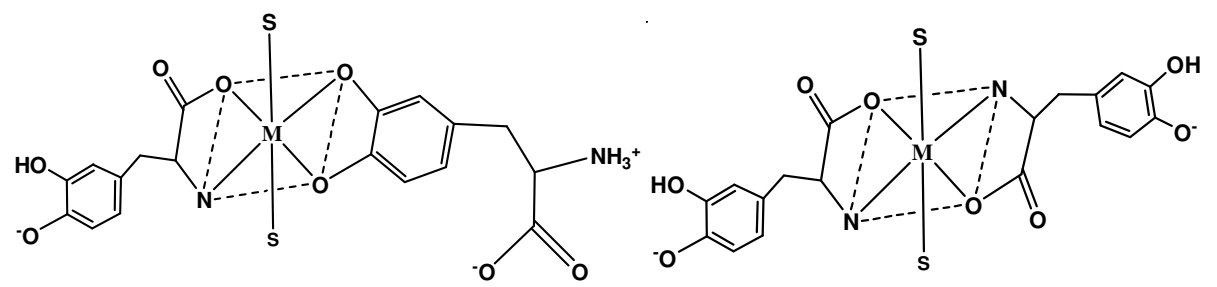

(II)

(I)

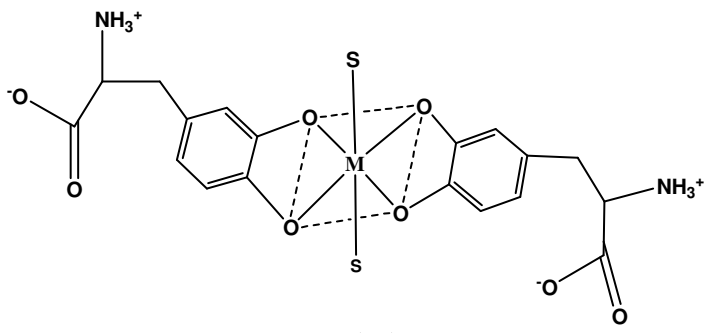

(III)

Figure 4. Possible modes of bonding in $\mathrm{ML}_{2} \mathrm{H}_{2}{ }^{2-}$.

\section{CONCLUSIONS}

The following conclusions have been drawn from the modeling studies of the speciation of binary complexes of $\mathrm{Co}(\mathrm{II}), \mathrm{Ni}(\mathrm{II})$, and $\mathrm{Cu}$ (II) with L-dopa in dioxan-water mixtures: (1) L-dopa forms both protonated and unprotonated complexes under a $\mathrm{pH}$ range of 1.6-11.0. (2) The binary species formed due to the interaction of dopa with metals are $\mathrm{CoL}, \mathrm{CoLH}, \mathrm{CoL}_{2}, \mathrm{CoL}_{2} \mathrm{H}$, $\mathrm{CoL}_{2} \mathrm{H}_{2}, \mathrm{NiLH}, \mathrm{NiL}_{2}, \mathrm{NiL}_{2} \mathrm{H}, \mathrm{NiL}_{2} \mathrm{H}_{2}, \mathrm{CuL}, \mathrm{CuLH}, \mathrm{CuL}_{2}, \mathrm{CuL}_{2} \mathrm{H}$, and $\mathrm{CuL}_{2} \mathrm{H}_{2}$. These models are validated by statistical treatment of data. (3) The linear variation of stability constants as a function of mole fraction of the medium indicates the dominance of electrostastic forces over non-electrostatic forces. (4) Some species are stabilised due to electrostatic interactions and some are destabilized due to the decreased dielectric constant. (5) The order of ingredients influencing the magnitudes of stability constants due to incorporation of errors in their concentrations is alkali > acid > ligand > metal. (6) Dopa is ambidentate ligand and it can bind through either amino acid side chain or phenolic groups depending on $\mathrm{pH}$. The present study $(<10 \mathrm{pH})$ favors the bonding through amino acid side chain. 


\section{REFERENCES}

1. Underwood, E.J. Copper in Trace Elements in Human and Animal Nutrition, 4th ed., Academic Press: New York; 1977; p 1.

2. Walker, W.R.; Reeves, R.; Brosanan, R.; Coleman, G. Bioinorg. Chem. 1977, 7, 271.

3. Kolodziej, A.F. The Chemistry of Metal-Containing Enzymes, Progress in Inorganic Chemistry, Vol. 41, John Wiley and Sons: New York; 1994; p 493.

4. May, P.M.; Linder, P.W.; Williams, D.R. J. Chem. Soc. Dalton 1977, 588.

5. Gergely, A.; Kiss, T.; Deak, G. Inorg. Chim. Acta 1979, 36, 113.

6. Pettit, L.D.; Powell, K.J. Stability Constants Database, Academic Software: Yorks, U.K.; 2000.

7. Birkmayer, W.; Horneykiewicz, O. Wien. Klin. Wschr. 1961, 73, 787.

8. Horneykiewicz, O. Wien. Klin. Wschr. 1963, 75, 309.

9. Mena, I.; Court, J.; Fuenzalida, S.; Papavasiliou, P.S.; Cotzias, G.C. New Eng. J. Med. 1967, $282,5$.

10. Rao, G.N.; Rao, R.S. J. Teach. Res. Chem. 1995, 2, 15.

11. Roderick, E.; Black, J. Assoc. Anal. Communit. Intern. (AOAC International) 2001, 84, 666.

12. "CHEC Chemical Summary: 1,4-dioxan". Children's Health Environmental Coalition. Retrieved 2006-02-02; http://healthychild.org/issues/media/.

13. "Report on Carcinogens, Eleventh Edition: Cobalt Sulfate". National Toxicology Program. Retrieved 2008-11-13; http://ntp.niehs.nih.gov/ntp/roc/eleventh/profiles/s048zcob.pdf.

14. Minot, G.R.; Murphy W.P. J. Am. Med. Assoc. 1983, 250, 3328.

15. Sigel. A.; Sigel. H.; Sigel, R.K.O. Metal Ions in Life Sciences, Vol. 2, John Wiley and Sons: Chichester, UK; 2007; p 702.

16. Hausinger, R.P. Microbiol. Rev. 1987, 51, 22.

17. Jaouen, G. Bioorganometallics: Biomolecules, Labeling, Medicine, Wiley-VCH: Weinheim; 2006.

18. Szilagyi, R.K.; Bryngelson, P.A.; Maroney, M.J.; Hedman, B.; Hodgson, K.O.; Solomon, E.I. J. Am. Chem. Soc. 2004, 126, 3018.

19. Thornalley, P.J. Biochem. Soc. Trans. 2003, 31, 1343.

20. Amount of copper in the normal human body, and other nutritional copper facts" Retrieved April 3, 2009; http://gravity.wikia.com/wiki/Copper.

21. National Research Council, Food Nutrition Board Recommended Dietary Allowances, National Research Council, Food Nutrition Board, NRC/NAS: Washington, D.C.; 1980; p 151.

22. Devi, K.V.S.; Raju, B.R; Rao, G.N. Acta Chim. Slov. 2010, 57, 398.

23. Rao. G.N.; Ramakrishna, A. Proc. Nat. Acad. Sci. India 2005, 75,245.

24. Gran, G. Anal. Chim. Acta 1988, 206, 111.

25. Gran, G. Analyst 1952, 77, 661.

26. Sailaja, B.B.V.; Kebede, T.; Rao, G.N.; Rao, M.S.P. Proc. Nat. Acad. Sci. India 2004, 74, 399.

27. Latha, M.P.; Rao, V.M.; Rao, T.S.; Rao, G.N. Bull. Chem. Soc. Ethiop. 2007, 21, 363.

28. Lavanya, K.V.; Rao, G.N.; Rajesh, M.; Babu, M.S. J. Indian Chem. Soc. 2004, 81, 384.

29. Rao, G.N. Ph.D. Thesis, Andhra University, Visakhapatnam, India, 1989.

30. Gans, P.; Sabatini, A.; Vacca, A. Inorg. Chim. Acta 1976, 18, 237.

31. Rao. G.N.; Ramakrishna, A. Proc. Nat. Acad. Sci. India 2005, 75, 245.

32. Born, M. Z. Phys. 1920, 1, 45.

33. Shinnichiro, S.; Kazuya, Y.; Nobuhumi, N.; Yuichi, T.; Hiro, K.; Tatsuya K. Inorg. Chim. Acta 1998, 283, 260.

34. Gergely, A.; Kiss, T. Metal Ions in Biological Systems, Vol. 9, Sigel, H. (Ed.), Dekker: New York; 1979; chap. 5, p 151.

Bull. Chem. Soc. Ethiop. 2011, 25(1) 